\title{
La constitución teórica del Estado-nación en el pensamiento político inglés del siglo XVII.
}

\author{
Angel Sermeño
}

\section{Introducción.}

Desde el época del Renacimiento hasta nuestro dias, no cabe duda, el pensamiento político occidental ha girado en torno a la problemática fundamental de la constitución, naturaleza y funcionamiento del Estadonación. Como todos sabemos, a partir de la génesis del modo de producción capitalista, los hombres se han visto lorzados a organizar sus relaciones de convivencia social bajo las normas dictadas por una institución superior a la que denominaron desde entonces Estado. En términos muy generales y descriptivos, pues, podemos decir que la categorla de Estado supone un determinado sistema político -normalmente representativo- constituido dentro de los límites precisos de un territorio nacional $y$ en donde existe un concreto ordenamiento jurldico-político soberano el cual se ejerce sobre un pueblo instalado en un área geohistórica y socioeconómica específica (1). Ahora bien, la soberanla, quizá la característica más configuradora del Estado, tiene una doble dimensión. A nivel interno se presenta como la instancia última de poder con capacidad de coacción legítima sobre el ciudadano particular. A nivel externo, a su vez, la soberanla se presenta como absoluta y no admite la jurlsdicción de cualquier tipo de normatividad exterior y superior a ella.

La problemática del Estado, en suma, ha dominado claramente la reflexión del pensamiento político occidental al menos hasta el siglo XIX. En la actualidad, ella continua siendo un problemática central, si bien ya 
no la única. Por razones obvias, no intentaremos discutir en el presente trabajo las principales cuestiones teóricas suscitadas en torno a la evolución de la categorla de Estado-nación. Ello supondrla nada menos que entrar en el análisis de toda la tradición del pensamiento político de los últimos cuatrocientos años (2). Nuestros objetivos son mucho más modestos. Unicamente deseamos explorar los orígenes conceptuales del Estado en el pensamiento político inglés del siglo XVII. Ello, en concreto, en el pensamiento del agudo y penetrante Thomas Hobbes en su obra cumbre Leviathan y del célebre John Locke en su también obra maestra Segundo ensayo sobre el gobierno civil. A partir de ahl nos gustarla mostrar, en un segundo momento, la continuidad de aquellos elementos conceptuales que presentes en el pensamiento de estos clásicos siguen teniendo vigencia contemporánea en la explicación y comprensión de la naturaleza del Estado.

A pesar de la anterior delimitación, ambos objetivos ofrecen sus propias dificultades. En primer término, el pensamiento político inglés del siglo XVII es sumamente rico, complejo y variado. Hobbes, en efecto, es sin duda alguna "el constructor de la primera teoría del Estado moderno" (3), caracterizada por su concepción absolutista; mientras que Locke representa el punto de partida del influyente pensamiento liberal. Nos encontramos, entonces, en un mismo siglo, esto es, separado por unos cuantos años, dos pensamientos que tienen un punto de partida común (que estriba en la justificación racional del nacimiento del Estado) pero que, no obstante, concluyen con resultados totalmente extremos. Uno, como decimos, absolutista y el otro liberal. Por ello, al comparar a ambos autores perseguiremos encontrar una explicación para ese paradójico resultado o, podrla ser, lograremos mostrar que por encima de las diferencias existe una continuidad profunda en el pensamiento de esos autores.

La dilicultad inherente al segundo objetivo radica en que, naturalmente, el pensamiento del siglo XVII no puede pretender dar cabal cuenta de las realidades politicas del presente. No obstante, el desaflo abierto consiste én determinar sl y en qué medida los supuestos teóricos del siglo XVII continuan modelando la organización social del presente.

\section{Contexto histórico.}

El Estado-nación nace, por supuesto, dentro de un contexto históricosocial especifico. El cambio de este contexto implica, por lo demás, un cambio en la propia concepción y realidad de la naturaleza del Estado. Cabe advertir que dicho cambio no se da támpoco de manera mecánica 
y unilateral. Como sea, en esta parte del trabajo mostraremos, en primer lugar, como el antecedente inmediato del contemporaneo Estado-nación se encuentra en el Estado absolutista el cual es, en concreto, la expresión de la transición histórica del feudallsmo al capitalismo. En segundo lugar, mostraremos como el pensamiento político de siglo XVII en Inglaterra obedece a los avatares propios sufridos de este modelo de Estado dentro de dicha sociedad.

\section{1) La conflguractón del Estado absolutista (1450-1720).}

Es ya de conocimiento común que entre el final del siglo $\mathrm{XV}$ y el principio del siglo XVIII la civilización europea, sobre todo central y occidental, sufrio una profunda transformación de todo orden: oconómico, social, cultural, etc. Esta transición, de una magnitud sin precedentes, marcó - como también ya sabemos- el paso de una sociedad feudal (eminentemente agraria) a una sociedad moderna (mercantilista) y modificó, naturalmente, la lisonomla europea. Ahora bien, Iraer rapidamente a cuenta este hecho no esta de más debido a que sus alcances e implicaciones fueron mucho más allá del contexto europeo al también haber prefigurado y sentado las bases del actual ordenamiento sociopolítico y económico de la humanidad entera.

De este proceso de transición lo que nos interesa rescatar en particular, también de forma rapida y descriptiva, es su dimensión política. Esto es, determinar las características de la constitución de los Estados nacionales europeos. Como sabemos tal proceso transcurrio de una manera lenta y conflictiva (4). Nacieron, en efecto, bajo unas condiciones políticas confusas e irregulares entre las que se destacan: la existencia de señorios que se traslapaban y cambiaban continuamente, no habla un legislador supremo, ni una soberania fuerte y no existia la distinción entre instituciones económicas y politicas. Bajo tales condiciones, los conflictos se resolvieron apelando primordialmente al recurso de la fuerza. El surgimiento de los Estados nacionales, bajo la modalidad específica del absolutismo, se vio obstaculizado, ante todo, por la existencia de intereses y ambiciones de las noblezas de cada pais que se encontraban, además, divididas. Las relaciones Iglesia-Estado, por su parte, no escaparon a la división y al conflicto. En tales relaciones fue usual que se manifestaran y resolvieran las contradiciones generadas por el desarrollo de la transición. No fue casual, en efecto, que los Estados nacionales se afirmaran no sólo frente a la nobleza sino también frente a la riqueza y el poderlo de las instituciones eclesiásticas.

De esta suerte y a pesar de que los procesos desencadenados por el 
capitalismo primitivo aumentaron, en magnitud e intensidad, la escala de las guerras, al estar precedidas todas ellas por motivaciones económicas, trajeron consigo, también, un aumento en la población y mejoras en el trasporte y el comercio. En esta étapa, el Estado se fortalecio internamente y entró a jugar un papel protagónico en todos los órdenes de la vida de la sociedad, pero sobre todo en el órden económico. En el marco de una intensa competencia por el control de la riquezas porvenientes del comercio, el Estado desempeño un papel proteccionista. Ante todo, creo un cuerpo de leyes a fin de reservar el comercio sobre todo colonial- y otros tráficos lucrativos para sus propios súbditos. Ello supuso, asimismo, la creación de aranceles externos y la eliminación de los internos y la creación de sociedades anónimas para impulsar la inversión. Una nueva racionalidad, entonces, se impuso de manera consistente sobre la base de una nueva actividad práctica de los hombres en el mundo. Como señala el historiador George Clark:

"el aumento de riqueza a través del comercio llevaba implícito, o mejor dicho, era un incremento de todas aquellas actividades que se llevaban a cabo mediante el trato comercial, las transacciones en dinero y los cambios basados en cálculos cuantitativos de utilidad. Significó una mengua de todas las actividades reguladoras por la costumbre, la tradición y la autoridad que no fueron regidas ya por el rango o la posición social, sino por el simple contrato" (5).

Bajo estos grandes lineamientos fue que se constituyó el modelo del Estado absolutista. Ahora bien, este, como sistema de Estado, no tuvo un desarrollo lineal ni uniforme, así como tampoco un único modelo puro. Existio, sin embargo, un sus diversas variantes -de la que en este trabajo nos interesa la inglesa - una unidad real fundamental que radicó en la aspiración de las naciones europeas a configurarse como una monarqula centralizada y fuerte. Todavla más importante que ello, el absolutismo supuso, como ya hemos insinuado, el aparecimiento de un conjunto de innovaciones institucionales que se volverlan típicas en las sociedades del capitalismo primitivo. Entre ellas se destacaron: la constilución del ejército, la burocracia administrativa, los impuestos, el florecimiento del comercio, como ya vimos en particular, y la diplomacia (6). El Estado absolutista, en suma, a lo largo de su génesis y desarrollo se encontro constante y profundamente sobredeterminado por el crecimiento del capitalismo. Constituido sobre una formación social mixta (nobleza y comerciantes), el Estado absolutista posibilitó, en definitiva, la consolidación de los intereses de las clases mercantiles y manulacturera. 


\section{2) La Inglaterra del siglo XVIl.}

La variante del absolutismo en Inglaterra, no obstante, mostró un desarrollo bastante partisular. En efecto, este se caracterizo por se corta duración y por los diversos limitantes que presento el modelo en su configuración concreta. Ante todo, las fuertes y progresivas contradicciones entre los intereses de las clases terratenientes y la de la ascendiente clase capitalista (comerciantes, artesanos y financieros) obstaculizaron constantemente y al final ahogaron la génesis del poder absolutista.

Lo anterior es importante de recalcar en este trabajo ya que si aceptamos la tesis del Perry Anderson según la cual el absolutismo constituyó más bien una adecuación de las estructuras políticas precapitalistas (feudales) a las nuevas condiciones históricas para proteger los privilegios y propiedades de la aristocracia; su corta carrera ascendente y su prematuro final en Inglaterra habrian allanado el carnino para la configuración de un sistema político y económico plenamente capitalista y libre de las últimas trabas del modo de producción anterior. No por gusto fue, en este sentido, Inglaterra la cuna de la revolución industrial y no tuvo necesidad de lanzarse a una profunda revolución politica burguesa como si fue el caso de Francia en donde el modelo absolutista encontro su formulación más clásica y consolidada (7).

Sea de lo anterior lo que fuere, 10 cierto es que el siglo XVII es trágico para el absolutismo en Inglaterra. Es, como sabemos, un siglo convulso dominado por las querrellas religiosas y por el forcejeo constante por el poder entre el Monarca y el Parlamento del que a la postre saldría victorioso este último. Dicha constante fue, sin duda, lo que inspiro el pensamiento político de Hobbes y de Locke. Como nos dice J.J Chevallier en este sentido:

"El furor de las disensiones religiosas - entre protestantes y catolicos, entre protestantes anglicanos y disidentes (o puritanos) - agravaba all' él furor de las pasiones politicas, formando todo ello una mezcla inextricable e incendiaria. En 1642 habla comenzado la lucha armada entre Carlos I Estuardo y su Parlamento, la mayoría puritana. Después de muchas peripecias, vencido el rey por el ejército parlamentario de Cromwell, habla sido ejecutado. 1651, Cromwell reina sobre Inglaterra, convertida en República (Commonwealth). Entonces aparecen en Londres un libro de extraño título: Leviathan: o la materia, la forma y la potencia de un Estado eclesiástico y civir (8).

Tales hechos nos indican, en efecto, que el pensarniento de Hobbes, en lo fundamental, va ha estar, como veremos a continuación, centrado en el problema de la unidad del Estado, el cual se encuentra amenaza- 
do tanto por discordias religiosas como por el enfrentamiento entre la Corona y el Parlamento. Hobbes, entonces, sin ser un político militante como sí lo fue Locke, lomara partido por la necesidad de afianzar la autoridad polltica y evitar la disgregación producida por la división del poder.

Locke, por su parte, nacio cincuenta años despues que Hobbes pero le toco vivir un escenario político igual de convulso al que tuvo aquel. De hecho, Locke asiste y toma claramente partido, por decilo de alguna manera, en el desenlace de estas querellas religiosas y políticas. Ciertamente, el corolario de estas disputas entre la Corona y el Parlamento será la victoria de Guillermo de Orange contra Jacobo II de la dinastia Estuardo.

"En noviembre de 1688, Guillermo, llamado por la inmensa mayoría del pueblo inglés y por la misma Iglesia oficial, llevando seiscientos navios y quince mil soldados, desembarca en las costas de Inglaterra. Por la libertad, por la religión protestante, por el Parlamento: tales son las palabras inscritas en las banderas del príncipe de Orange. No encuentra ninguna resistencia seria. La partida está definitivamente perdida para los Estuardo. Está definitivamente ganada por el Parlamento, que planteará sus condiciones al nuevo rey Guillermo. EI prolestantismo y el liberalismo Whigs han prevalecido sobre el catolicismo a lo Bossuet, sobre el absolutismo de derecho divino a lo Luis XIV, sobre la soberania absoluta y no compartida" (9).

El Segundo ensayo sobre el gobiemo civil, pues, aparece a finales del siglo XVII como la obra clásica del antiabsolutismo, esto es, de "el deseo violento de la autoridad contenida, limitada por el consentimiento del pueblo, por el derecho natural, a fin de eliminar el riesgo de despotismo, de arbitrariedad, aun exponiéndose a abir una brecha a la anarqula" (10). Expuesto todo lo anterior, es hora de que entremos en la materia central del trabajo.

\section{Hobbes: El Estado absoluto.}

El pensamiento político de Thomas Hobbes no puede menos que ser calificado de "lormidable" (11). Ante todo destacan en él las caracteristicas siguienles: su extraordinaria sislematicidad, su coherencia interna y su profundidad que hacen de dicha doctrina algo arrollador y de sus conclusiones algo casi inapelable. En realidad, el pensamiento de Hobbes es el que inaugura el modelo iusnaturalista para explicar el origen y el fundamento del Estado y de la sociedad política. Veamoslo a continuación. 


\section{1) Idea de hombre.}

El denominado estado de naturaleza es el artificio teórico a partir del cual el pensamiento político burgues explica el origen de la sociedad a partir de una visión individualista del ser humano. Esto significa, en conseduencia, que de una determinada concepción de hombre se derivara una concepción, también particular, de sociedad y Estado.

Hobbes, como es bien sabido, tiene una concepción "materialista" de la naturaleza humana. Es decir, para Hobbes el hombre es "por naturaleza" un ser egolsta, calculador, precavido y, por lo mismo, temeroso. Un individuo con tales características encuentra su felicidad de una manera muy sui generis consistente en buscar y ambicionar constantemente el acceso y el uso del poder. Las riquezas, el honor o cualquier otra forma de manifestación del poder son incesantemente los moviles de los hombres en su trato con los demás. Con estas premisas, obviamente, no puede menos que desenvocarse en un situación de total caos y anarquia. Esto es, una situación "natural" y perpetua de guerra de todos contra todos en donde sulrir el mal mayor que es la muerte violenta se encuentra siempre al acecho. En palabras del propio Hobbes:

"A la tendencia natural que lleva a los hombres a destrozarse mutuamente, la cual deriva de sus pasiones, pero más que todo de su vanidad, agreguemos ahora el derecho de todos a todo, que permite atacar y defenderse con el mismo derecho y que es el orlgen de los celos y de las eternas sospechas de todos contra todos. Si consideramos además cuán difficil es guardarse de los enemigos, aun poco numerosos y mal armados, cuando atacan con la intención de adelantársenos y oprimimos, es imposible negar que el estado natural de los hombres, antes que se hubiesen constituido en sociedad, fue la guerra, y no la guerra simplemente, sino la guerra de todos contra todos. ¿Acaso no es la guerra ese tiempo en el cual hechos y dichos manifiestan suficientemente la voluntad de contender por la violencia? El resto del tiempo se llama paz" (12).

La guerra, pues, es un mal terrible. Su amenaza de muerte violenta, su carácter perpetuo y, sobre todo, la ausencia de normas que regulen la inevitable competencia entre los hombres hace, en consecuencia, la necesidad de construir el Estado. En el estado de naturaleza los hombres son fundamentalemnte iguales y gozan de los mismos derechos y prerrogalivas. Justamente, esta situación es la que origina la situación de confrontación de todos contra todos. Los hombres entonces se ponen de acuerdo para renunciar y delegar su poder nalural en un tercero que es el Estado bajo la convicción de que este último impondra la estabilidad y normatividad que garanticen, ante todo, evitar el peligro de la muerte violenta. 


\section{2) El Estado-Leviathan.}

El origen de la sociedad civil y de su ente regulador por excelencia, El Estado se encuentra, por tanto, en el acuerdo y el consenso común de los hombres. Asi es como se consigue la transición del estado de naturaleza a la sociedad. Se trata, en consecuencia, de un acto "racional", voluntario de los seres humanos en cuanto seres individuales interesados en salir de su estado natural. El Estado, pues, es consebido como una construcción social, producto de la cultura $y$, en definitiva, un ser "artificial". Como nos lo dice el propio Hobbes:

"... el arte del hombre... puede fabricar un animal artificial... Más aún: el arte puede imitar al hombre, esa obra maestra racional de la Naturaleza. Pues obra del arte es, ciertamente, ese gran Leviathan que se llama cosa pública o Estado (Commonwealth), en latín Civitas, y que no es otra cosa que un hombre artificial, aunque de una talla mucho más elevada y de una fuerza mucho mayor que las del hombre natural, para cuya protección y defensa ha sido imaginado. En él, la soberanía es un alma artificial, puesto que da la vida y el movimiento al cuerpo entero... La recompensa y el castigo... son sus nervios. La opulencia y las riquezas de todos los particulares son su fuerza. Salus populi, la salud del pueblo, es su función... La equidad y las leyes son para él una razón y una voluntad antificiales. La concordia es su salud, la sedición su enfermedad, y la guerra civil, su muerte. En fin, los pactos y los contratos que, en el origen, presidieron a la constitución, a la agrupación y unión de las partes de este cuerpo politico se parecen a este fiat o hagamos al hombre que pronunció Dios en la creación" (13).

El cálculo interesado de los individuos egolstas y temerosos es la inspiración del contrato o pacto social que funda el órgano artificial del Estado. Sus principales y necesarias características derivaran tanto de la naturaleza del ser humano como de las condiciones bajo las cuales se concibe el contrato originario. Para Hobbes, en efecto, el Estado sera un ente soberano, absoluto e indivisible. Su voluntad va a sustituir y a representar la voluntad de todos y cada uno de aquellos que se acogen a su protección y salvaguarda. De nuevo con Hobbes:

"La unión asl creada se llama Estado, o sea sociedad civil y también persona civil. Dado que la voluntad de todos es reducida a una sola debe tenerse por una persona; $y$, por la palabra "una" debe distinguirse y diferenciarse de todos los hombres particulares, como teniendo sus derechos y bienes propios. De modo que ni el conjunto de los ciudadanos, ni uno de ellos, si excepluamos a aquel cuya voluntad reemplaza la voluntad de todos, debe ser considerado como 
el Estado. El Estado, pues, ha de ser definido como una persona única cuya voluntad, en virtud de los pactos hechos entre muchos hombres, debe considerarse como la voluntad de lodos ellos y que puede, por consiguiente, utilizar las fuerzas y los bienes de cada uno para la paz y defensa común" (14).

El Estado en Hobbes es el garante de la paz. Ello es posible por que el Estado representa y ejerce el poder absoluto en virtud de que todos los individuos han consentido sometersele. Debe destacarse que en el pensamiento de Hobbes dicha renuncia es definitiva e irrevocable toda vez que el Estado cumpla con su misión de mantener el orden y la estabilidad social. Finalmente, además de absoluto e irrevocable, el poder del Estado es indivisible. Estos tres atributos del Estado se resumen en una sola caracterlstica: la soberanla. Revisemos rapidamente cada uno de estos atributos.

El acto que da constitución al Estado es irrevocable debido a que una vez cedidos los derechos naturales del individuo a un tercero no es posible, por una parte, volver a obtener la unanimidad para disolver la unión; mientras que, por otra, tampoco es esperable que el soberano ya constituido admita sin más su disolución. A este, en efecto, no se le puede desposeer de su autoridad. Como argumenta Bobbio, al respecto:

"La imposibilidad de derecho deriva de haberse concebido el pacto de unión como un contrato en favor de un tercero, es decir, como un contrato en el que los signalarios asumen una obligación, no sólo uno con el otro, sino también con el lercero en cuyo favor se ha estipulado el contrato, La naturaleza de este contrato es tal que no puede rescindirse sólo con el consenso de las partes, sino que hace falta también el acuerdo del tercero, con el que las partes se han reciprocamente obligadas. Esto significa que, una vez establecido el pacto de unión, para rescindirto no basta el acuerdo de los asociados, ya de hecho improbable porque es necesaria la unanimidad de los votos, sino que también es necesario el consenso del mismo soberano" (15).

Ahora bien, para Hobbes el que la soberanía sea absoluta significa que el poder es ejercido por el Estado sin ningún tipo de limitaciones, ya sean estas internas o externas. La implicación práctica de este hecho estriba en que los contratantes están sometidos completamente a la jurísdicción y al poder del Estado. Ciertamente, estos es asi por que los sujetos contratantes han cedido sus derechos naturales de forma total y absoluta al Estado. De hecho, el único derecho que han guardado para sí es el derecho a la vida, el cual por definición es irrenunciable. De nuevo con Bobbio: 
"para dar vida al Estado civil cada individuo ha de renunciar a su derecho sobre todas las cosas y a la fuerza para mantenerlo. Como consecuencia de la renuncia al derecho sobre todas las cosas, al individuo que ha entrado a formar parte del Estado, que se ha convertido en súbdito, no le queda otro derecho que el derecho a la vida. Que el derecho a la vida sea irrenunciable deriva de la lógica misma del sistema: asl como los individuos instituyen el Estado para escapar de la amenaza permanente de muerte que caracteriza al estado de naturaleza, es decir, para mantener a salvo la vida, pueden considerarse desligados del vínculo de la obediencia cuando su vida este en peligro a causa del soberano" (16).

De lo anterior se sigue que el individuo esta sometido a lo que el Estado dicte como ley, mientras que, por su parte, el Estado no se encuentra sujeto a las leyes que él mismo ha dictado. En suma, pues, el Estado se encuentra la posición de dar y al mismo tiempo de quebrantar la ley. Asl, inexorablemente, el Estado dicla ilimitadamente la leyes y el subdito obedece indisculiblemente a las mismas.

Un poder absoluto no puede, por lo demás, ser un poder divisible. En la concepción de Hobbes, el poder es uno. Se combate, desde esta perspectiva, la teoria del gobierno mixto. Según Hobbes la división de los poderes soberanos en el seno del Estado unicamente pueden acarrear su misma degeneración y destrucción. Recordemos que la problemática a la que responde todo el pensamiento político Hobbesiano es la existencia de la anarquia, las revueltas y la guerra civil. Como señala, en este sentido, Chevallier:

"El absolutismo de la soberania entraña en Hobbes su indivisibilidad y la despectiva repulsa de todo gobierno mixto. Dividir el poder es disolverlo. Los fragmentos del poder se destruyen mutuamente; se convierten en otras tantas facciones, en otras tantas personas soberanas" (17).

Poner en tela de juicio el poder soberano no es otra cosa, pues, que disolver el Estado. Según Hobbes, cuando el Estado es débil, nada puede hacer que los súbditos renuncien a su derecho natural absoluto de protegerse a sI mismos. $O$, lo que es similar, de buscar otro protector para comprometerse con él.

De esta suerte, entonces, hemos desarrollado en su puntos centrales la teoría política de Hobbes. Veamos ahora el pensamiento de Locke.

\section{Locke: Individuo, libertad y propiedad.}

Los historiadores del pensamiento político coinciden en descatar que 
el pensamiento de Locke no es tan sislemálico y profundo como el de Hobbes. Sin embargo, afirman que su impacto e influencia ha sido mucho más honda que la de aquel. En realidad, Locke consiguio imponer sus -novedosos y revolucionarios, para su época- principios teóricos en la práctica política de una forma sorprendente. Por supueslo, como ya señalamos, el principio esencial sobre el que gira toda la obra de Locke es su lucha contra el absolutismo. En efecto, la acepción común del Estado liberal, inaugurada por Locke, es aquella según la cual el Estado tiene poderes y funciones limitadas. La base de tal concepción radica en el postulado de que todos los hombres poseen por naturaleza un conjunto de derechos fundamentales: a la vida, a la libertad, a la felicidad, a la seguridad, a la propiedad, etc. $Y$, en tal perspectiva, el ejercicio legitimo del poder por parte del Estado no puede bajo ninguna justificación violar o cooptar la vigencia de estos derechos. Además, el Estado debe ejercitar su poder basandose en el consentimiento de los gobernados el cual, de ser ignorado da paso al derecho de insurrección del pueblo. Desarrollaremos, entonces, estos planteamiento un poco más ampliamente.

\section{1) La fundamentaclón de los derechos naturales universales.}

Locke también adopta en su pensamiento el punto de vista iusnaturalista. Esto es, parte como Hobbes del estado de naturaleza y del contrato originario para justificar y fundamentar un preciso ordenamiento social y juridico. Obviamente, ofrece una versión radicalmente nueva ellos. Las variaciones en la teorla del estado de naturaleza y del contrato de Locke con relación a la concepción de Hobbes radican en los puntos siguientes (18):

a. El estado de naturaleza es pacífico, no belicoso.

b. El contrato social es un contrato suscrito entre los individuos en beneficio de la colectividad pero no a favor de un tercero (lease el Estado en su concepción absoluta).

c. El contrato puede disolverse cuando el pueblo no encuentre garantizado el respelo a sus derechos individuales o cuando el ejercicio del poder por parte del Estado adquiera carácter despótico.

d. Finalmente, la naturaleza del poder politico derivado del contrato es siempre limitada y divisible. Nunca absoluta e indivisible.

Sobre las misma nociones de Hobbes, entonces, pero introducciendo variantes radicales, Locke va a lundar los principios que rigen la libertad política. Veamos como lo plantea: 
"Con la finalidad de comprender bien en qué consiste el poder polftico y para remontamos a su verdadera fuente, será necesario que consideremos cuál es el estado en que se encuentran naturalmente los hombres, a saber: un estado de completa libertad para ordenar sus actos y para disponer de su propiedades y de sus personas como mejor les parezca, dentro de los limites de la ley natural, sin necesidad de pedir permiso y sin depender de la voluntad de otra persona. Un estado de igualdad es aquel dentro del cual todo poder y toda jurisdicción son recíprocos, en el que nadie tiene más que otro, puesto que no hay cosa más evidente que el que seres de la misma especie y de idéntico rango, nacidos para participar sin distinción de todas las ventajas de la Naturaleza y para servirse de las mismas facultades, sean también iguales entre ellos, sin subordinación ni sometimiento" (19).

En el estado de naturaleza los individuos se encuentran en una situación de complela libertad e igualdad y ello es asi por que se encuentran regidos por la razón natural, norma legisladora de este estado primigenio. Recordemos que Locke sostiene ya en la primeras líneas de su ensayo que si bien el estado de naturaleza es de completa libertad no es del predominio de la licencia. La razón natural, ante todo, dicta que los seres humanos pueden vivir en perfecta convivencia respetando su vida, propiedad, salud o libertad. No nos encontramos, pues, un estado de guerra y en caso de una violación a dicha ley natural exisle el derecho de castigar al transgresor con el único fin de reparar el daño causado e impedir que vuelva a repetirse. Esto significa que el castigo sera siempre proporcional a la violación inflingida.

No obstante, a pesar de ser una condición pacífica, el estado de naturaleza presenta algunas imperfecciones e insuliciencias en orden a garantizar una socialización segura y estable. Aunque no lo sostiene explicitamente, para Locke el estado de naturaleza se encuentra siempre bajo un equilibrio inestable y provisional, esto es, bajo un límite crítico que amenaza seriamente el mantenimiento de la libertad, de la igualdad natural y del goce pacífico de la propiedad. Básicamente, eslas insuficiencias estriban, en primer término, en la "carencia de leyes establecidad, conocidas, recibidas y aprobadas por consentimiento común". En segundo término, de "jueces reconocidos e imparciales que tuvieran por función la aplicación de las leyes establecidas". Y, finalmente, por sobre todo, de un "poder coactivo capaz de asegurar la ejecución de los juicios fallados" (20). Ello hace necesario, en consecuencia, el recurso al pacto social y a la fundación del cuerpo político. 


\section{2) El consentimiento, origen del Estado.}

Se trata aquil de un punto esencial en el pensamiento de Locke. La fundación del cuerpo polftico se da, pues, sobre la base exclusiva del consentimiento libre y voluntario de sus asociados. Hablamos de un consentimiento que se da única y exclusivamente para garantizar no la paz, como en Hobbes, sino el pleno disfrute de los derechos naturales. Sobre todo del derecho a la propiedad. En palabras de Locke:

"Siendo, según se ha dicho ya, los hombres libres, iguales e independientes por naturaleza, ninguno de ellos puede ser arrancado de esa situación y sometido al poder politico de otros sin que medie su propio consentimiento. Este se otorga mediante convenio hecho con otros hombres de junlarse e integrarse en una comunidad destinada a permitirles una vida cómoda, segura y pacifica de unos con otros, en el disfrute tranquilo de sus bienes propios y una salvaguardia mayor contra cualquiera que no pertenezca a esa comunidad" (21).

Locke esta afirmando, en consecuencia, una tesis que contradice de raíz la pretención abosolutista de fundar el cuerpo político sobre la presunta auloridad del poder paternal o sobre el discutido derecho de conquista. Para Locke, solamente el consentimiento de hombres libres puede fundar un poder político legítimo. Lo importante es que el consentimiento otorgado esta sujeto a condicionamientos. Ante todo no supone una renuncia total a los derechos naturales originarios. Estos fundamentales derechos subsisten, no desaparecen y cumplen, justamente, con la función de "limitar el poder social y fundar la libertad" (22).

\section{3) La división de poderes y el derecho de insurrección.}

La justificación de la división de poderes surge de la misma condición del. hombre antes de efectuar el contrato social. En el estado de naturaleza el hombre, dice Locke, goza de dos tipos diferentes de poderes. Uno, el poder de hacer todo lo que juzgue a propósito para su conservación y para la conservación del resto de los hombres. $Y$, dos, el poder de castigar los crimenes cometidos contra las leyes naturales. Por tanto, en el momento de constituir la sociedad civil el hombre se despoja de ambos poderes que entrega en herencia y provecho de la misma sociedad.

"Así -explica Chevallier-, la sociedad heredera de los hombres libres del estado de naturaleza posee, a su vez, dos poderes esenciales. Uno es el legislativo, que regula cómo las fuerzas de un Estado deben ser empleadas, para la conservación de la sociedad y de sus 
miembros. El otro es el ejecutivo, que asegura la ejecución de la leyes positivas en el interior. En cuanto al exlerior, los tratados, la paz y la guerra constituyen un tercer poder ligado, por lo demás, normalmente al ejecutivo, y que Locke llama federativo" (23).

La división de poderes, dice Locke, es el mejor freno para evitar la tentación de abusar del poder por parte de quienes lo detentan, ya sean estos personas o instituciones. Además, la división del poder es lo que otorga agilidad al poder ejecutivo para que se encuentre siempre dispuesto a hacer cumplir las leyes. Pues bien, admitida la división de poderes, Locke procede a jerarquizarla debidamente. El poder legislativo sera el poder supremo y al cual el ejecutivo debera subordinarse. De hecho, el ejecutivo no es concebido, naturalmente, como un poder exclusivamente subalterno.

"En beneficio de la sociedad, se requiere que exisla cierta flexibilidad, de tal manera que a la discreción de quien liene el poder ejecutivo se pueda actuar sobre lo que el legislativo no puede prever, 0 en los casos en que la aplicación estrecha y rigida de las leyes es capaz de provocar más perjuicio que beneficio" (24), explica Chevallier.

Locke culmina su obra, finalmente, con la justilicación del derecho de insurrección del pueblo. La división de poderes, en efecto, es también condición para que los derechos naturales de los individuos se mantengan vigentes. El uso del poder por parte de los órganos respectivos, en el pensamiento de Locke, es por definición límitado. No existe ninguna excusa para el ejercicio arbitrario del poder. La única y exclusiva finalidad del poder es la de defender la vida y la propiedad. Esto significa, en otras palabras, que la entrada en vigor del poder no puede jamás extenderse más allá de lo que el bien público exige. Como nos dice el propio Locke:

"El poder legislativo supremo... (esta) sometido a las restricciones siguientes: En primer lugar, no es ni puede ser un poder absolutamente arbitrario sobre las vidas y los bienes de las personas. No siendo sino el poder conjunto de todos los miembros de la sociedad, que se ha otorgado a la persona o asamblea que legisla, no puede ser superior al que tenlan esas mismas personas cuando vivlan en estado de Naturaleza, antes de entrar en sociedad, poder que renunciaron en favor de la comunidad politica. Nadie puede translerir a otro un poder superior al que él mismo posee... No puede, pues, el legislador sobrepasar ese poder que le entregan. El poder del legislador llega únicamente hasta donde llega el bien público de la socie$\operatorname{dad}^{\mathrm{N}}(25)$. 
En suma, pues, para Locke, la fuente del poder es el pueblo. Es cierto que, normalmente, éste lo delega pero bajo situaciones de opresión o sumisión puede y debe recuperarlo. Esto significa que el pueblo es un juez respecto del uso o mal uso del poder por parte de quienes los reciben. En consecuencia, se encuentra totalmente justificado que el pueblo emplee la fuerza cuando los poderes mal ejercidos han perdido autoridad y legitimidad.

\section{A modo de conclusión: Hobbes y Locke ¿Continuidad o dis- continuidad?}

Para concluir el presente trabajo no vamos a realizar una comparación exhaustiva de las diferencias y semejanzas en el pensamiento de Hobbes y Locke. Ello de alguna manera ha quedado ya esbozado implfcitamente en las partes anteriores. En realidad, como señala, en uno de sus recientes libros, José Femandez Santillan existe, por ejemplo, mayor cercanía sistemática y conceptual entre Hobbes y Rousseau (26) que entre Hobbes y Locke. Como hemos visto, no cabe ninguna duda al respecto, son filosoflas políticas diametralmente opuestas. Es cierto que ambas parten de un mismo marco conceptual $y$, en general, de unos mismos supuestos teóricos configurados en torno al modelo del iusnaturalismo. Pero las radicales diferencias se explican, entonces, a partir de las diferentes interpretaciones que nuestros filósofos hacen de dichos supuestos comunes. Aquí, quizá, lo verdaderamente curioso estriba en ver como dos espíritus geniales interpretan con agudeza y originalidad los avatares de un mismo siglo, rico en conflictos políticos y que tuvieron como resultado final la liquidación de los últimos vestigios feudales y el arrivo triunfal del modo de producción capitalista.

Sobre esta base histórica, sin embargo, autores como C.B. Macpherson en su ya clásica obra La teoria política del individualismo posesivo. De Hobbes a Locke si verían una continuidad teórica entre Hobbes y Locke. Por supuesto, se trata de una continuidad muy particular y precisa. De acuerdo a dicha obra, lo que unificaría o, mejor dicho, establecería el puente entre dos pensamientos tan radicalmente alejados seria el que ambos compartirian un muy profundo supuesto unificador (27). Este supuesto sería el de partir de una concepción de la naturaleza humana fundada en lo que Macpherson denomina Individualismo posesivo y, paralelamente, una concepción del nexo social como sociedad posesiva de mercado. Nuestro autor todavia va más allá al asegurar que las raíces de la contemporanea concepción democrática-liberal del Estado y la sociedad hunden sus raíces en el pensarniento político inglés del siglo XVII. Para Macpherson: 
"En los últimos años se ha escrito mucho sobre la dificutad de enconIrar una base teorética sólida para el estado democrático liberal. Como la dificultad persiste, parece que vale la pena preguntarse si no puede residir tanto como en el desarrollo posterior en las ralces de la tradición liberal. Para una investigación asl, puede considerarse adecuadamente que las raíces están en la teoria y en la práctica politicas del siglo XVII inglés. Fue entonces cuando, en el curso de una prolongada lucha en el Parlamento, de una guerra civil, de una serie de experimentos republicanos, de una restauración de la monarquía y de una revolución constitucional final, se desarrollaron todos los principios que habrian de convertirse en fundamentales para la democracia liberal, aunque, en aquella época, no todos con el mismo éxilo" (28).

Según Macpherson la concepción individualista del ser humano serla, por tanto, el punto de unión y de partida tanto del pensamiento de Hobbes como del de Locke. Aquel y no éste sería el iniciador de la concepción individualista burguesa del ser humano, a pesar de que, paradójicamente, sus conclusiones hayan sido tan antiliberales. Como sea, el punto es que para Macpherson, "Hobbes -al igual que Lockeinfirió los derechos y las obligaciones políticas del interés y la voluntad de los individuos disociados" (29). Ahora bien, una concepción tal de individuo exige una correspondiente concepción de sociedad, misma que también va a ser compartida por Hobbes y Locke. De esta suerte:

"El individuo es libre en la medida en que es el propietario de su propia persona y de sus capacidades. La esencia humana es la liberlad de la dependencia de las voluntades ajenas, y la libertad es función de la posesión. La sociedad se convierte en un hato de individuos libres iguales relacionados entre si como propietarios de sus propias capacidades y de lo que han adquirido mediante el ejercicio de éstas. La sociedad consiste en relaciones de intercambio entre propietarios. La sociedad política se convierte en un artifício calculado para la protección de esta propiedad y para el mantenimiento de una relación de cambio debidamente ordenada" (30).

Compartir ambos supuestos, junto a las peculiaridades especificas del momento hisiórico vivido por los autores es lo que explica, asimismo, dice Macpherson, sus tan disimiles puntos de llegada en sus respectivas teorlas.

Hobbes hace en el Leviathan, según Macpherson, una consideración de la sociedad desde el punto de vista de las simples y llanas relaciones mercantiles. Por ello es que su teoría concluye en el más radical absolutismo. Esto es, Hobbes estarla respondiendo a la necesidad de encon- 
Irar un ente supremo que regulara las relaciones mercantiles en ese momento del desarrollo del modo de producción capitalista. $Y$, como vimos en la segunda parte de este trabajo, en cierto momento de su historia el estado absolutista, acertada o desacertadamente, entró en la tarea de regular y reglamentar la actividad comercial y la ascendente actividad indusirial. En efecto:

"El modelo de mercado posesivo —que subyace en el Leviathanexige una estructura legal coercitiva. Cómo mínimo, la vida y la propiedad han de quedar aseguradas, y los contratos han de ser definidos e impuesta su ejecución. El modelo admite también una acción estatal que vaya mucho más allá de este mínimo. El Estado puede controlar el uso de la tierra y el uso del trabajo, interferirse en el libre flujo del comercio mediante restricciones y derechos arancelarios, fomentar un tipo de industria y desalentar otra... etc" (31).

El pensamiento de Locke, por su parte, responde a otra necesidad social del nuevo modo de producción en auge. La "hazaña" lograda por el modelo teórico de Locke radica, más bien, en dar a la apropiación burguesa 0 , si se prefiere, a la acumulación originaria de capital una base moral justificadora. En suma, pues, Locke:

"Partiendo del supuesto tradicional de que la tierra y sus frutos hablan sido entregados originalmente a la humanidad para su uso común, dio la vuelta a cuantos derivaban de este supuesto teorlas restrictivas de la apropiación capitalista. Minó la descalificación moral con que hasta entonces se habla visto lastrada la apropiación capitalista ilimitada. Aunque sólo hubiera hecho esto, su hazaña tendría que calificarse de considerable, pero hizo todavia más. Justificó también, como naturales, una diferencia de clases en derechos y en racionalidad, $y$ al hacerlo proporciono una base moral positiva a la sociedad capitalista" (32).

A la luz de lodo lo anterior surge, ciertamente, una constatación fundamental. Esta es que entre absolutismo y liberalismo no existe una distancia tan grande como es común creer. $Y$, en otra dimensión de este mismo hecho, que entre liberalismo y democracia las relaciones son más complejas de lo que también aparentan ser (33). Para finalizar, en definitiva, como ya dijimos en la introducción, no puede esperarse que los principios politicos centrales del siglo XVII explique al mundo contemporaneo del siglo XX. Lo cierto es que, sin embargo, a pesar de los cambios sufridos y las complejidades de nuestra época continuamos viviendo en una sociedad capitalista en donde las relaciones de mercado configuran la totalidad del mundo y donde, también, el trabajo humano sigue siendo una posesión alienable. Tanto Hobbes como Locke si- 
guen siendo pensadores "actuales" a partir de los cuales podemos repensar, explicar y comprender nuestras propias problemáticas a la hora de organizar nuestra convivencia social cotidiana. Aqul estriba, en suma, nuestra provicional y modesta conclusión de toda la discusión anterior.

\section{Notas bibliográfices.}

1. Cerroni, U. Polfica: métodos, teorlas, procesos, sujetos, instituciones y categorfas, México, Siglo XXI, 1992, pag. 127.

2. J.J Chevallier sostiene que en ese amplio periodo de cuatro siglos las diversas concepciones del Eslado-nación pueden agruparse en cuatro categorlas, a saber: aquellas que justifican el absolutismo monárquico (Maquiavelo, Bodino, Hobbes y Bossuet); las que ofrecen un movimiento inverso contrario al absolutismo (Locke, Montesquleu, Rousseau y Sleyes); las que surgen como consecuencla Inmediata de la Revolución francesa (Burke, Fichte y Tocqueville); y, tinalmente, aquellas nacidas desde 1848 hasta la segunda guerra mundial (Marx-Engels, Maurras, Sorel, Lenin y Hitler).

Chevallier, J.J. Las grandes textos politicos. Desde Maquiavelo a nuestros dias, Madrid, Aguilar, 1901, pags. X-XI.

3. Bobbio, N. Thomas Hobbes, México, Fondo de Cultura Económica, 1992 pag. 7.

4. Clark, G. La Europa modema 1450-1720, México, Fondo de Cultura Económica, 1986.

5. Ibid. pag. 182.

6. Anderson, P. El Estado absolutista, México, Siglo XXI, 1987.

7. Hobsbawm, E. Las revoluciones burguesas, Madrid, Guadarrama.

8. Chevallier ... Ob. Cit.. pags. 50-51.

9. Ibid. Pag. 89.

10. Ibid. pag. 90 .

11. Macpherson, C.B. La teoria polftica del individualismo posesivo, Barcelona, Fonlanella, 1970, pag. 21.

12. Hobbes, T. Antologia, Barcelona, Península, 1987. pag. 202.

13. '-------. Leviathan, México, Fondo de Cultura Económica, 1980, pag. 3.

14. -----.. Antologia, Ob. Cit... pag. 232.

15. Bobbio... Ob. Cit. pag. 53.

16. Ibid. pag. 56.

17. Chevallier... Ob. Cit... pag. 59. 
18. Bobbio... Ob. Cil... pag. 16-17.

19. Locke, J. Segundo ensayo sobre el gobiemo civil, México, Nuevomar, 1993, pag. 32-33.

20. Chevallier... Ob. Cit... pag. 95.

21. Locke... Ob. Cit... pag. 72.

22. Chevallier... Ob. Cit. pag. 97.

23. Ibid. pag. 96.

24. Ibid.

25. Locke... Ob. Cil. pag. 87.

26. Fermandez Santillan, J. Hobbes y Rousseau, México, Fondo de Cultura Económica, 1992.

27. Norberto Bobbio opina que la tesis de Macpherson es, con todo, allamente discutible. A nuestro juicio, sin embargo, es una tesis sugerente y merece, por tanto, ser reflexionada a londo.

Bobbio... Ob. Cit...

28. Macpherson... Ob. Cit... pag. 15.

29. Ibid. pag. 16.

30. Ibid. pag. 16-17.

31. Ibid. pag. 58-59.

32. Ibid. pag. 191.

33. Bobbio, N. Liberalismo y democracia, México, Fondo de Cultura Económica, 1989. 